\title{
Description and Microbiology of Endotracheal Tube Biofilm in Mechanically Ventilated Subjects
}

\author{
Pierre-Eric Danin MD, Emmanuelle Girou PharmD, Patrick Legrand MD, \\ Bruno Louis PhD, Redouane Fodil PhD, Christo Christov MD, Jérôme Devaquet MD, \\ Daniel Isabey $\mathrm{PhD}$, and Laurent Brochard MD
}

\begin{abstract}
BACKGROUND: A biofilm is found on the inner side of endotracheal tubes (ETT) in mechanically ventilated patients, but its features and role in pneumonia remain unclear. METHODS: This prospective, observational, monocentric study included critically ill ventilated subjects. Measurement of the ETT inner volume was first performed before extubation using the acoustic reflection method. After extubation, the biofilm was studied by means of optical and atomic force microscopy. Bacteriological analysis was then performed and compared with clinical documentation. RESULTS: Twenty-four subjects were included. Duration of intubation lasted from 2 to $79 \mathrm{~d}$ (mean \pm SD: $11 \pm 15 \mathrm{~d})$. The mean percentage of ETT volume loss evaluated in situ $(n=21)$ was $7.1 \%$ and was not linked with the duration of intubation. Analyses with atomic force microscopy $(n=6)$ showed a full coverage of the inner part of the tube with biofilm, even after saline rinse. Its thickness ranged from 0.8 to $5 \mu \mathrm{m}$. Bacteriological cultures of the biofilm $(n=22)$ often showed the same bacteria as in tracheal secretions, especially for pathogenic organisms. Pseudomonas aeruginosa and Candida albicans were among the most frequent microorganisms. In subjects who had experienced a successfully treated episode of ventilator-associated pneumonia $(n=5)$, the responsible bacteria were still present in the biofilm. CONCLUSIONS: ETT biofilm is always present in intubated patients whatever the duration of intubation and appears quickly after intubation. Even after soft rinse, a small but measurable part of biofilm remains always present, and seems strongly adherent to the ETT lumen. It contains potentially pathogenic bacteria for the lung. Key words: biofilm; endotracheal tube; ventilator-associated pneumonia. [Respir Care 2015;60(1):21-29. (c) 2015 Daedalus Enterprises]
\end{abstract}

\section{Introduction}

Ventilator-associated pneumonia (VAP) is the most commonly reported nosocomial infection among ICU patients, and is associated with increased morbidity, possibly mortality, and excess costs. ${ }^{1}$ VAP occurs in $8-28 \%$ of all

Drs Danin, Drs Devaquet, and Brochard are affiliated with Service de réanimation médicale, Centre Hospitalier Universitaire (CHU) Henri Mondor, Créteil, France; Drs Danin, Louis, Fodil, Isabey, and Brochard are affiliated with Unité Institut National de la Santé et de la Recherche Médicale (INSERM) U955, Fonctions Cellulaires et Moléculaires de l'Appareil Respiratoire et des Vaisseaux, Equipe Biomécanique Cellulaire et Respiratoire, Faculté de Médecine de Créteil, Paris 12, Créteil; Dr Girou is affiliated with the Unité de Contrôle, Epidémiologie et Prévention de l'Infection, CHU Henri Mondor, Créteil; Dr Legrand is affiliated with the Laboratoire de bactériologie-virologie, CHU Henri Mondor, Créteil; Dr Christov is affiliated with the Département Anatomie pathologique, Unité INSERM U955, CHU Henri Mondor, Créteil, France; intubated patients, and its incidence increases with the duration of ventilation. ${ }^{2,3}$

The endotracheal tube (ETT) appears to be an independent risk factor for VAP by impairing mucociliary clearance, disrupting the cough reflex, and promoting the ac-

\footnotetext{
Dr Brochard is affiliated with Keenan Research Centre, St Michael's Hospital, Toronto, and the Interdepartmental Division of Critical Care Medicine, University of Toronto, Toronto, Ontario, Canada.
}

Supplementary material related to this paper is available at http:// www.rcjournal.com.

The authors have disclosed no conflicts of interest.

Correspondence: Pierre-Eric Danin MD, 151 Route de St Antoine de Ginestière, BP 3079, 06202 Nice cedex, France. E-mail: danin.pe@ chu-nice.fr.

DOI: $10.4187 /$ respcare. 02722 
cumulation of tracheobronchial secretions in the lung. ${ }^{2,4,5}$ Contaminated secretions from the oropharynx and the gastrointestinal tract are also a source of VAP through repeated microaspirations. ${ }^{2}$ The inner face of the endotracheal tube can thus be a reservoir for microorganisms, providing them a surface to adhere to and to produce biofilm. Biofilm is a thin layer of microorganisms that adhere to the surface of an organic or inorganic structure and produce exopolysaccharides, which protect organisms from antibiotics and the immune system. ${ }^{6,7}$ ETT biofilm and airway colonization ${ }^{8}$ seem to appear very quickly after intubation and could be a significant source of bacterial inoculation in the lung.9-11 Aggregates can secondarily be detached spontaneously or during suctioning, bronchoscopy, or respiratory care..$^{9,12-14}$

New approaches have been proposed to prevent biofilm formation such as antiseptic-coated ETTs or the use of devices designed to remove the mucus from the ETT lumen. ${ }^{15-18}$ Data about the existence of endotracheal tube biofilm in mechanically ventilated patients, however, are scarce. The aim of our study was to try to observe the presence of biofilm, some of its characteristics, and its microbiology. We first estimated the inner volume reduction of the ETTs in vivo during mechanical ventilation, then microscopically examined the inner surface of these ETTs after extubation, and compared bacteria bound on the ETT with clinical data, especially in subjects having experienced VAP during the course of mechanical ventilation.

\section{Methods}

\section{Subjects}

Critically ill ventilated patients hospitalized between January and June 2008 in the 25-bed medical ICU of Henri Mondor University Hospital (Creteil, France) and requiring invasive mechanical ventilation for $>8 \mathrm{~h}$ were eligible for the study at the time of the extubation and prospectively screened. Patients were excluded if they were $<18$ y old, intubated $<48 \mathrm{~h}$, extubated during the night, the weekend, or another non-workday.

For all study subjects, the following characteristics were recorded at the time of ICU admission: age, gender, concomitant diseases, hospital-admission diagnosis, indication for mechanical ventilation, severity of illness based on Simplified Acute Physiology Score II (SAPS II), and previous antibiotic therapy.

The diagnosis of VAP was made in accordance with criteria from American Thoracic Society guidelines ${ }^{19}$ (new radiologic picture, purulent aspirate, decline in oxygenation, positive culture with pathogenic microorganisms, systemic signs of sepsis without another origin, leukocytosis), and was confirmed with quantitative microbiological

\section{QUICK LOOK}

\section{Current knowledge}

The inner face of the endotracheal tube can be a reservoir for microorganisms, providing them a surface to adhere to and produce biofilm. Biofilm is a thin layer of microorganisms that adhere to the surface of an organic or inorganic structure and produce exopolysaccharides, which protect organisms from antibiotics and the immune system. ETT biofilm develops quickly after intubation and could be a significant source of bacterial inoculation in the lung.

\section{What this paper contributes to our knowledge}

Endotracheal tube biofilm is always present in intubated patients regardless of the duration of intubation and appears quickly after intubation. Even after a soft rinse, a small but measureable biofilm remains strongly adherent to the ETT lumen. This biofilm contains potentially pathogenic bacteria for the lung.

criteria based on invasive respiratory secretion samplings as described previously. ${ }^{20}$ Microorganisms considered as having high potential pathogenicity included Staphylococcus aureus, Enterobacteriaceae, Pseudomonas, and yeast. Enterococcus colonization was also recorded. Microorganisms such as coagulase-negative staphylococci including Staphylococcus epidermidis, Streptococci viridans, and diphtheroid bacilli were not considered to be of high pathogenic potential. Nursing care protocols regarding endotracheal intubation and oropharyngeal hygiene in critically ill subjects were as follows: tracheal suctioning was made every $4 \mathrm{~h}$ (or more only if necessary), subjects were kept in a semirecumbent position, the mouth was washed with oral chlorhexidine, the endotracheal cuff pressure was maintained at approximately $25 \mathrm{~cm} \mathrm{H}_{2} \mathrm{O}$, heated humidifiers were preferred to heat and moisture exchangers for long duration of ventilation, and a protocol for sedation was applied. A physician and a physiotherapist were present at the time of each extubation.

The institution's clinical investigation ethics committee approved the study protocol (Comite de Protection des Personnes, Ile-de-France IX), and, due to the purely observational nature of the study, requirement for informed consent was waived.

\section{Study Design}

Just before the planned extubation, a measurement of the reduction of the inner diameter of the endotracheal tube was performed by the acoustic method for compari- 
son with the diameter of a clean tube (see following paragraph), and a tracheal suctioning sample was collected. After extubation, the tube was kept in a sterile environment for subsequent examination. After the first 6 ETTs, the remaining tubes were rinsed in a standardized way with saline solution (dip rinsing for $10 \mathrm{~s}$ ) to remove labile tracheal secretions, leaving a substantial sample in the lavage fluid.

\section{Measurements of the Inner Volume of the Endotracheal Tube}

The ETT area internal profile was evaluated by the 2-microphone acoustic method as described previously. ${ }^{21,22}$ Briefly, the device used consisted of 2 microphones (8510-B piezoresistive pressure transducers, Endevco, Le Près SaintGervais, France) and a horn driver mounted on a wave tube (overall length $22 \mathrm{~cm}$, internal diameter $8 \mathrm{~mm}$ ) connected to the ETT connector. The other end of the wave tube was open to the atmosphere, allowing the subject to breathe spontaneously (see the supplementary materials at http://www.rcjournal.com). A pressure wave was generated by the horn driver. The resulting pressure in the wave tube was recorded via the microphones in a microcomputer. The area was inferred using a deconvolution algorithm in the frequency domain. Such a setup was able to measure the area of a 50-cm-long ETT, as well as the location of any obstruction. ${ }^{23}$ The measurement procedure consisted of connecting the wave tube and recording the pressure. In total, it took $<45 \mathrm{~s}$. The results were expressed on a graph, where length was on the $\mathrm{x}$ axis and area on the y axis. The ascending end of the curve represented the opening of the tube in the airway (Fig. 1). The ETT inner volume was estimated by integrating the inner area along the longitudinal axis, and was compared with the same unused and clean tube. The difference was expressed as a percentage of the clean area in net volume.

\section{Bacteriological Examination}

After extubation, the ETT was cut in a sterile area, in 3 1-cm segments (distal: just below the cuff; subglottic: just above the cuff; and proximal: at the 20-cm mark). Each segment of the ETT was then homogenized by vortex in Digest-Eur (Eurobio, Courtaboeuf, France). An aliquot of the solution was then spread on different culture plates (trypticase soy agar, blood agar with nalidixic acid and colistin methanesulfonate agar, blood agar, Drigalski agar, chocolate agar), for different dilutions (pure, 1/100, and $1 / 1,000$ ), and incubated for $48 \mathrm{~h}$. Globally as well as for individual species, bacterial counts were determined, and bacterial identification and susceptibility testing were performed with standard methods. Tracheal secretions ob-

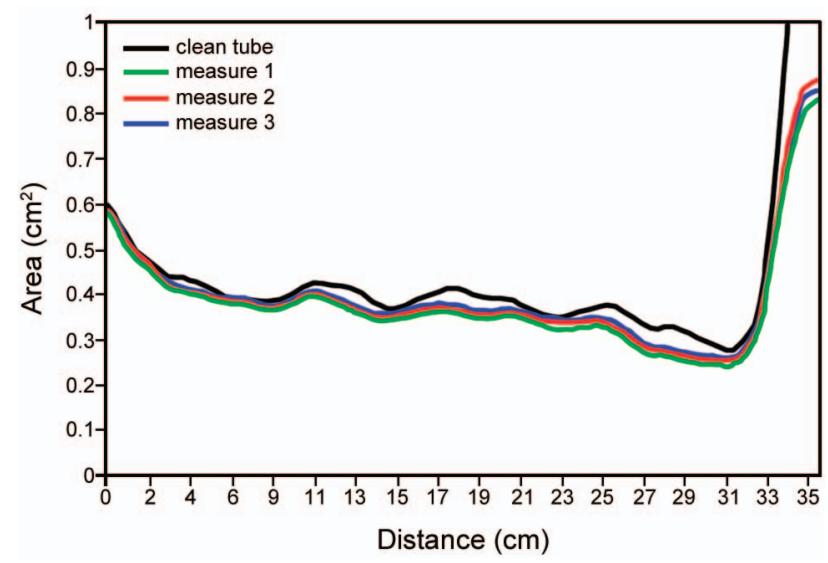

Fig. 1. Example of Iongitudinal area profile of the endotracheal tube (ETT) measured with the acoustic method in a single subject (subject 19) and compared with a clean tube of same diameter taken as reference (ETT diameter: 7.5). The area is plotted in square centimeters on the $y$ axis versus the longitudinal distance plotted in centimeters on the $\mathrm{x}$ axis (from the vent connector to the lung). The obstruction is represented by the lowering area in the $y$ axis.

tained just before extubation were cultured on the same Colombia agar plates as described above.

\section{Atomic Force Microscopy}

Atomic force microscopy (AFM) imaging is performed by sensing the force between a very sharp microscopic probe and the sample surface. The sample is mounted on a piezoelectric scanner, which ensures 3-dimensional positioning with high resolution. The force is monitored by attaching the probe to a pliable cantilever, which acts as a spring, and measuring the bending, or deflection, of the cantilever by a laser beam (see the supplementary materials at http://www.rcjournal.com). ${ }^{24}$

For the study, the distal segment of the endotracheal tube was fixed with glutaraldehyde, eventually after dip rinsing by saline solution as described under "Study Design." A 1-mm portion of this prepared sample was cut and glued on a microscope plate, then placed in the AFM (NanoWizard, JPK Instruments, Berlin, Germany) in aqueous solution (phosphate-buffered saline). An optical microscopic view was first performed for marking.

\section{Statistical Analysis}

A Mann-Whitney test was used to compare inner diameter reductions obtained with the acoustic method. A Spearman's correlation coefficient was used to correlate obstruction of ETT and duration of ventilation. Bacterial counts, expressed as $\log 10$ transformed number of colonyforming units $/ \mathrm{mL}$ of secretion, were compared on the 3 segments of tube (distal, medial, and proximal) with a 


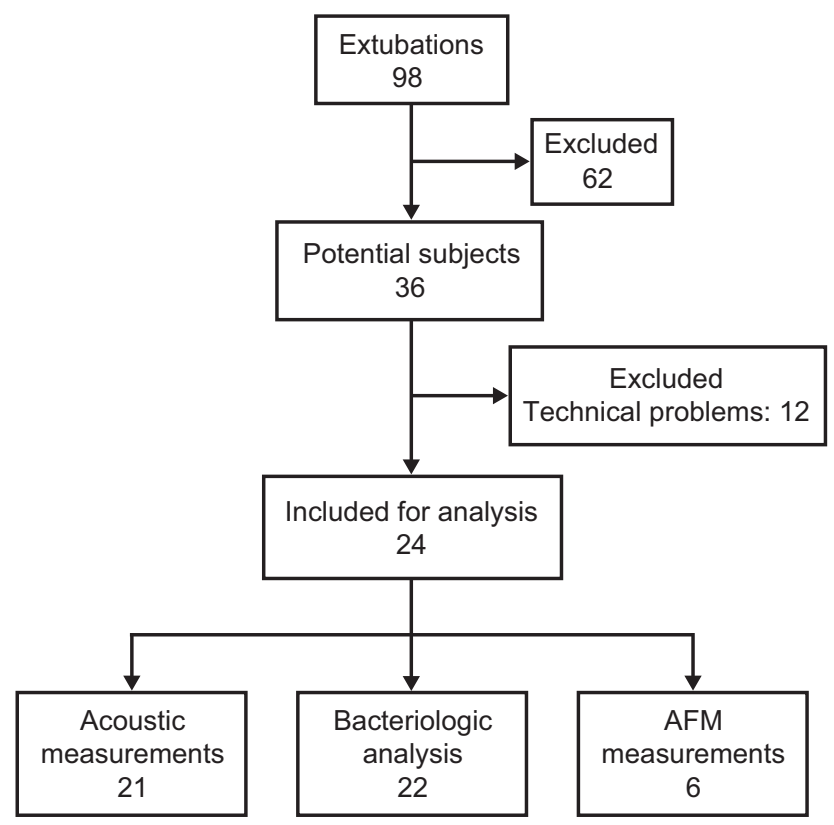

Fig. 2. Flow chart of the study. AFM = atomic force microscopy.

Wilcoxon matched-pair signed rank test. All $P$ values were 2-tailed, with significance set at .05.

\section{Results}

\section{Study Population}

Ninety-eight subjects were extubated in the unit during the study period, and 24 endotracheal tubes were considered for the evaluation (Fig. 2). All subjects were orotracheally intubated with high-volume, low-pressure cuffed, polyvinyl chloride tubes (Rüsch Super Safety, Duluth, Georgia) except in one subject (No. 13) (Mallinckrodt medical tube, Neunkirchen-Seelscheid, Germany). ETT internal diameters ranged from 7 to $8 \mathrm{~mm}$. Five subjects included in the study were diagnosed with VAP, with 4 having bacteriological documentation. The median duration of mechanical ventilation was $7.5 \mathrm{~d}$. Details of the subjects studied are provided in Table 1.

\section{Obstruction Measurement}

Measurements could be performed just before extubation for 21 subjects, and were not possible in 3 for technical reasons. The mean ETT volume loss compared with a clean tube amounted to $7.1 \% \pm 4.5$. No relationship was observed between the ETT internal volume loss and the duration of mechanical ventilation $(\rho=-0.093, P=.68$; see Fig. 3) or with the type of humidification system (heat and moisture exchangers or heated humidity), nor according to the presence or absence of VAP (data not shown).

\section{Bacteriological Results}

During the study, 22 endotracheal tubes were analyzed. Results of the bacteriological cultures did not depend on the segment of the tube analyzed (proximal, medial, or distal). No relationship was found between bacterial burden and the duration of intubation (data not shown).

$P$. aeruginosa was the predominant organism found in the ETTs (58\%). Three subjects had previously developed a VAP episode due to this organism. S. epidermidis was frequently isolated, but not considered as having pathogenicity for the lung. C. albicans was isolated in $25 \%$ of cases, each time associated with P. aeruginosa (Table 2).

Five subjects had experienced a VAP during intubation, due to $P$. aeruginosa for 3 subjects (subject 2, 10, and 19), Alcaligenes xylosoxidans for 1 subject (subject 4), and clinically diagnosed but with no adequate initial sampling for 1 subject (subject 21). One subject had experienced a hospital-acquired pneumonia (subject 19). The microorganisms responsible or supposed responsible for pneumonia were always found in ETT biofilms, despite the fact that these subjects had received an adequate and successful antibiotic course before extubation (Table 3 ).

\section{Microscopic Views}

Cells observed with optical microscopy were compatible with those found in tracheal secretions: macrophages, apoptotic cells, and lymphocytes. Microorganisms were also present (Fig. 4). The samples were uniformly covered with biofilm, except the lateral parts, possibly due to scratching during preparation (Fig. 5).

Atomic force microscopy provided 3-dimensional views for 6 samples and confirmed the integral coating of the tube even after soft saline rinse for the last 2 AFM samples. The layer was inhomogeneous, from approximately 0.8 to $5 \mu \mathrm{m}$ of thickness (Fig. 6; see also the supplementary materials at http://www.rcjournal.com), irrespective of the duration of intubation (2-79d).

\section{Discussion}

In this observational single-center study, we describe the macroscopic and microscopic features of the ETT biofilm, using the acoustic reflection technique, optical microscopy, and AFM for imaging the ETT biofilm in clinical study. In parallel, bacterial colonization of the ETT biofilm was compared with clinical history.

Using the acoustic method, we confirmed a mean intraluminal volume loss, $\sim 7.1 \%$ for the entire endotracheal tube, which corresponds to an inner thickness of aggregate around approximately $0.5 \mathrm{~mm}(500 \mu \mathrm{m})$. The assessment of ETT internal area by acoustic reflectometry has been in use for several years, and appears suitable to estimate, 
Table 1. Baseline Subjects' Characteristics

\begin{tabular}{|c|c|c|c|c|c|c|c|}
\hline Subject No. & Age (y) & Sex & $\begin{array}{l}\text { Duration of } \\
\text { Intubation (d) }\end{array}$ & Comorbidity & Reason for Intubation & $\begin{array}{l}\text { Inner Diameter } \\
\text { ETT }(\mathrm{mm})\end{array}$ & SAPS II \\
\hline 1 & 30 & M & 4 & NA & Pneumonia & 8 & 20 \\
\hline 2 & 68 & $\mathbf{M}$ & 21 & COPD, cardiopathy & Cerebral stroke & 8 & 43 \\
\hline 3 & 74 & M & 3 & Hypertension & Pulmonary edema & 8 & 27 \\
\hline 4 & 31 & $\mathbf{M}$ & 79 & Tetraplegia & Pneumonia & 8 & 28 \\
\hline 5 & 56 & M & 8 & COPD, cardiopathy & Cardiopulmonary failure & 8 & 29 \\
\hline 6 & 23 & M & 9 & Trisomia, kidney transplant, dialysis & Septic shock & 8 & 62 \\
\hline 7 & 66 & $\mathrm{~F}$ & 9 & Leukemia & Pneumocystis pneumonia & 8 & 28 \\
\hline 8 & 44 & $\mathrm{~F}$ & 4 & Cardiopathy, obesity & Cerebral stroke & 7.5 & 29 \\
\hline 9 & 75 & M & 2 & Dialysis & Pulmonary edema & 7.5 & 70 \\
\hline 10 & 24 & $\mathbf{M}$ & 15 & NA & Pneumonia & 8 & 19 \\
\hline 11 & 58 & M & 5 & Parkinson's disease & Neurological failure & 8 & 30 \\
\hline 12 & 67 & M & 3 & Cirrhosis & Neurological failure & 8 & 55 \\
\hline 13 & 78 & M & 3 & Pulmonary fibrosis & Cardiac arrest & 8 & 45 \\
\hline 14 & 72 & M & 6 & Cardiopathy & Pulmonary edema & 7.5 & 64 \\
\hline 15 & 67 & $\mathrm{~F}$ & 2 & NA & Pulmonary edema & 7 & 54 \\
\hline 16 & 49 & M & 15 & COPD, cardiopathy, lymphoma & Cardiopulmonary failure & 8 & 41 \\
\hline 17 & 70 & M & 6 & Dialysis & Septic shock & 8 & 46 \\
\hline 18 & 86 & M & 14 & COPD, cardiopathy & Pneumonia & 8 & 57 \\
\hline 19 & 63 & $\mathbf{F}$ & 10 & Cirrhosis & Septic shock & 7.5 & 47 \\
\hline 20 & 56 & M & 6 & Cardiopulmonary disease & Hemorrhagic shock & 7.5 & 60 \\
\hline 21 & 18 & $\mathbf{F}$ & 13 & NA & Pneumonia & 7.5 & 57 \\
\hline 22 & 68 & M & 8 & Cardiopathy & Cardiac arrest & 8 & 69 \\
\hline 23 & 51 & M & 14 & Liver transplant & Cerebral stroke & 8 & 57 \\
\hline 24 & 76 & M & 7 & COPD & Pulmonary edema & 8 & 39 \\
\hline Mean \pm SD & $57 \pm 19.4$ & & $11.1 \pm 15.3$ & & & & $44.8 \pm 15.7$ \\
\hline \multicolumn{8}{|c|}{$\begin{array}{l}\text { Subjects with VAP are in bold type. Subject } 18 \text { experienced a hospital-acquired pneumonia. } \\
\text { SAPS II = Simplified Acute Physiology Score II } \\
M=\text { male } \\
F=\text { female } \\
\text { NA = not applicable }\end{array}$} \\
\hline
\end{tabular}

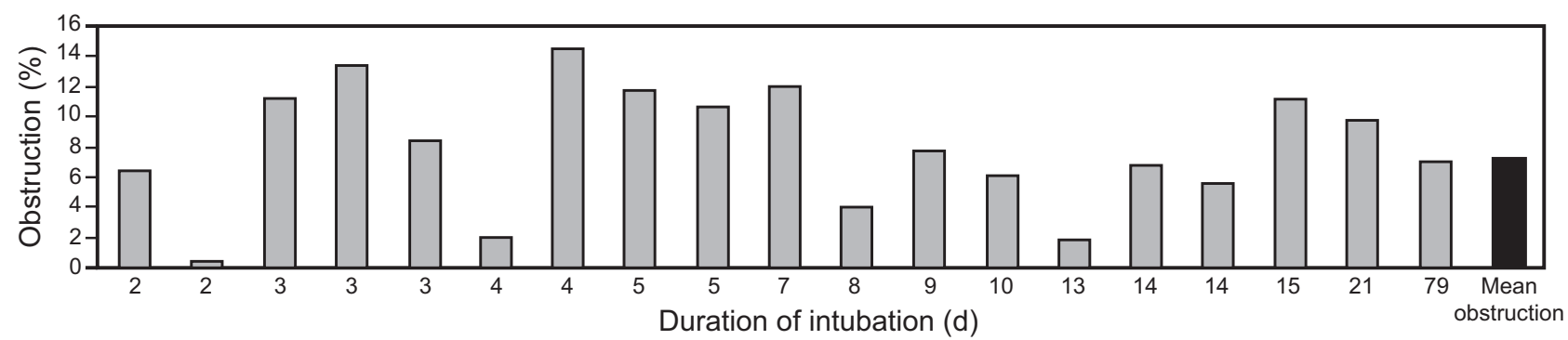

Fig. 3. Percentage of tube obstruction according to the duration of intubation. Each bar represents a single subject (measurements could only be performed for 19 subjects; see text).

even under severe ICU conditions, an ETT obstruction in vivo. ${ }^{21,23}$ However, this experimental technique has some limitations: fluctuation of the signal and progressive narrowing of the measured area. Therefore, the study ETT needs to be compared with an unused one studied in the same conditions. A major obstruction was never observed, probably because adequate airway humidification was provided, as poor humidification is associated with a high incidence and degree of tube obstruction. ${ }^{23,25} \mathrm{We}$ did not observe any relationship between obstruction and duration of intubation, history of VAP, or humidification systems.

Our results are in accordance with previous studies, regarding the percentage of endotracheal tube occlusion. A study comparing different airway humidification systems with the same method as used by us suggested that prolonged use of humidification systems results in progres- 
Table 2. Frequency of Organisms Isolated in Tracheal Tube Biofilm

\begin{tabular}{lc}
\hline \hline Cocci Gram-Positive & \\
Staphylococcus aureus & 29 \\
Staphylococcus coagulase negative & 45.8 \\
Enterococcus species & 29 \\
Streptococcus species & 50 \\
Bacilli Gram-Negative & \\
Pseudomonas aeruginosa & 58.3 \\
Acinetobacter baumannii & 4.2 \\
Klebsiella pneumoniae & 12.5 \\
Proteus mirabilis & 8.3 \\
Enterobacter species & 8.3 \\
Citrobacter species & 8.3 \\
Morganella morganii & 8.3 \\
Candida albicans & 25
\end{tabular}

Data are given as percentage of analyzed tubes.

Table 3. Comparison Between Clinical Documentation (Tracheal Sample) and Bacterial Culture of Endotracheal Tube Biofilm in Subjects With Hospital (Subject 18) or Ventilator-Acquired Pneumonia (Subjects 2, 4, 10, 19, and 21)

\begin{tabular}{|c|c|c|}
\hline Subject & Tracheal Aspirate & $\begin{array}{c}\text { Microorganisms in } \\
\text { Biofilm }\end{array}$ \\
\hline 2 & Pseudomonas aeruginosa & P. aeruginosa \\
\hline \multirow[t]{6}{*}{4} & Candida albicans & C. albicans \\
\hline & Stenotrophomonas maltophilia & S. maltophilia \\
\hline & Alcaligenes xylosoxidans & A. xylosoxidans \\
\hline & Staphylococcus aureus & NA \\
\hline & Proteus mirabilis & NA \\
\hline & Enterobacter aerogenes & NA \\
\hline \multirow[t]{2}{*}{10} & P. aeruginosa & P. aeruginosa \\
\hline & C. albicans & C. albicans \\
\hline 18 & P. aeruginosa & Pseudomonas aeruginosa \\
\hline \multirow[t]{2}{*}{19} & P.aeruginosa & P. aeruginosa \\
\hline & C. albicans & C. albicans \\
\hline 21 & No documentation & $\begin{array}{l}\text { Acinetobacter baumannii, } \\
\text { methicillin-resistant } \\
\text { S. aureus, S. maltophilia, } \\
\text { Streptococcus mitis, } \\
\text { non-albicans Candida }\end{array}$ \\
\hline
\end{tabular}

Except for subject 21, the same microorganisms were found in both sites.

sive reduction of ETT volume with duration of intubation, to a greater extent with heat and moisture exchangers $(5.5 \%)$ than with heated humidity $(3.3 \%){ }^{23}$ A common inadvertent obstruction of $\sim 15 \%$, was found by Boque et al, ${ }^{26}$ which was significant as early as $24 \mathrm{~h}$ following intubation. Another study based on ETT air flow resistance after extubation showed that ETT narrowing was associated with the duration of ventilation, without statistical differences between 2 humidifier devices. ${ }^{27}$ Shah and Kollef ${ }^{28}$ found a

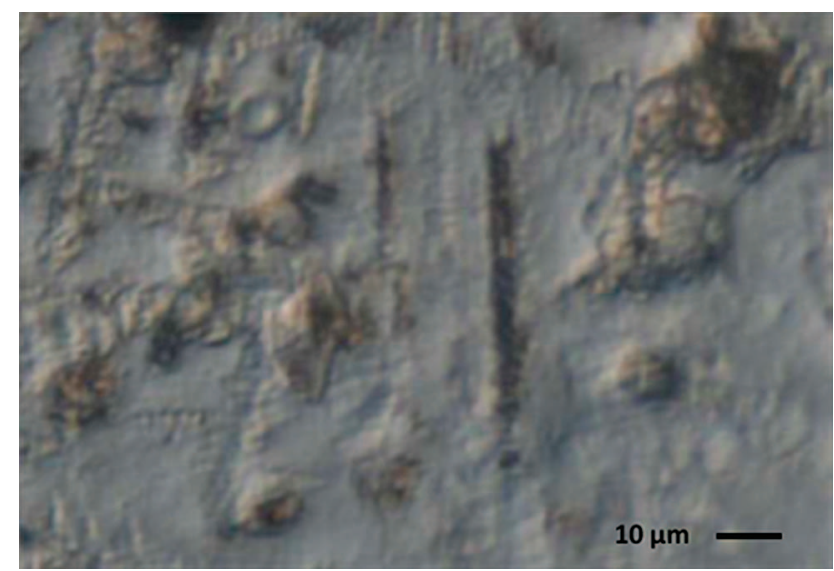

Fig. 4. Microscopic view of biofilm on endotracheal tube.

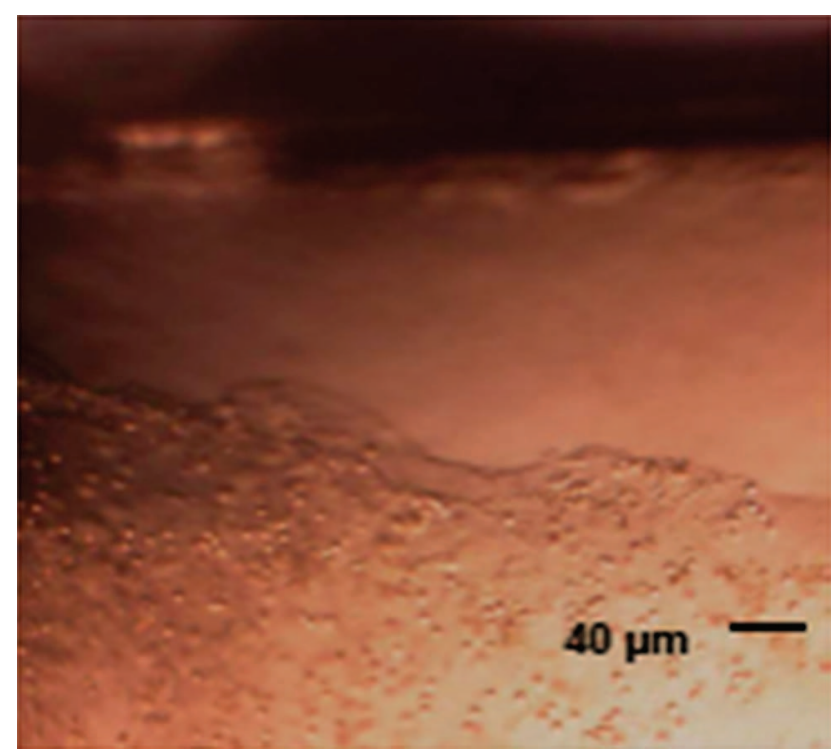

Fig. 5. Optical view of biofilm. On the border of the sample, the biofilm is torn artifactually during the preparation, leaving the tube uncovered.

$10 \%$ intraluminal volume loss increased with prolonged tracheal intubation, even if measurements were performed up to $5 \mathrm{~d}$ after extubation. In a subsequent study, Wilson et $\mathrm{al}^{29}$ showed a large degree of resistance, occurring in all sizes of ETT, unpredictable regarding the duration of intubation, and beginning immediately in some subjects.

The first views of ETT biofilm were described in 1986, using electronic microscopy, and an integrally covered inner side of the tube was found in $84 \%$ of cases. ${ }^{11}$ Berra and co-workers ${ }^{15,30}$ studied ETT biofilm from animals ventilated for $24 \mathrm{~h}$, and found $750 \mu \mathrm{m}$ of thickness using electron microscopy and $65 \mu \mathrm{m}$ with confocal microscopy. In a clinical trial using confocal microscopy, the same authors demonstrated an accumulation of biological material within the ETT, ranging from 0 to $700 \mu \mathrm{m} .{ }^{31} \mathrm{We}$ 


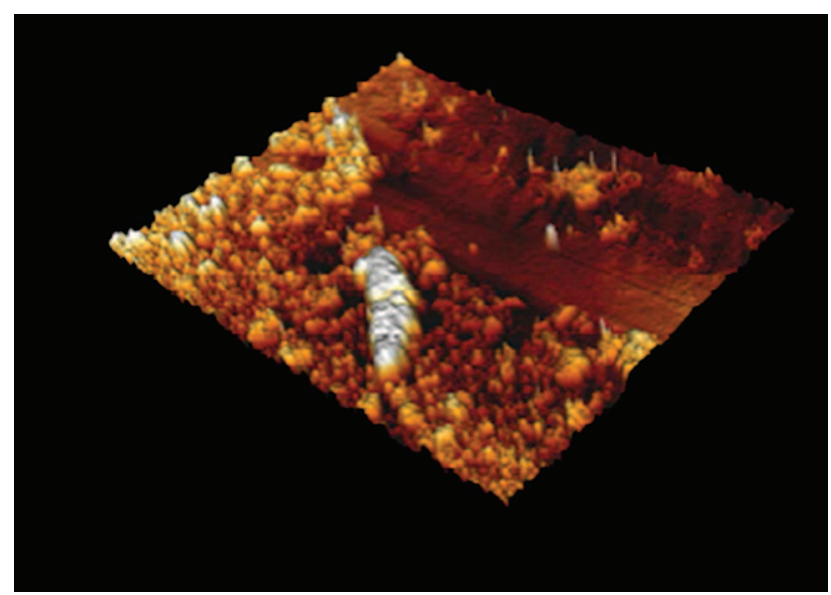

Fig. 6. Three-dimensional view of the biofilm with AFM. The plane part represents the surface of the tube. The length of the sample is $\sim 50 \mu \mathrm{m}$.

observed a global covering of the internal side of the ETT with optical microscopy and AFM. The thickness was found to be $\sim 2.5 \mu \mathrm{m}$, but seemed to vary with the presence of bacteria, yeast, or cells. Covering was also observed after a very short duration of intubation.

A biofilm usually corresponds to a bacterial production of exopolysaccharides, which adhere to each other, and constitute a protected mode of growth for bacteria that allows survival in a hostile environment, in a slow-growing or starved state. During ventilation, the ETT is progressively covered by accumulation of respiratory secretions, comporting cell fragments, immune cells, and microorganisms, termed biofilm by several authors. ${ }^{32}$ In our study, labile secretions were removed at least partially by the fixation solution, so we decided to first rinse out the ETT softly to remove this labile part of humid secretions. We studied only the deeper layer on the ETT, where bacteria can develop under tracheal secretions secondarily deposited. In this way, the thickness differs if tracheal secretions deposited in ETT are measured (acoustic measurement) or not (AFM after rinsing). The acoustic measurement, performed in situ, takes into account the viscous part of tracheal secretions that remain on the inner side of the tube, whereas the AFM measurement performed after a soft wash does not. This could explain the difference of thickness between the measurements in our study (500 or $2.5 \mu \mathrm{m})$ and between the thickness described in precedent studies. ${ }^{17,30,31,33}$ Indeed, we demonstrate that a part of biofilm still covers ETT despite rinsing.

AFM imaging is a recent technique never used, to our knowledge, on this sort of support. Examination was possible only for 6 ETTs, owing to the complexity of measurement and availability of the equipment. Large forces act between the probe and the sample during AFM imaging, and may reduce the image resolution and cause sur- face damage or displacement in case of multiple scanning in the same place, limiting the reproducibility of this technique. Moreover, the AFM biofilm measurements were performed on a 1-mm sample, which might not be representative of the entire ETT despite a location with optical microscopy. To eliminate contamination of glutaraldehyde by labile secretions, a first rinse by saline solution was performed for the last 2 AFM samples. Nevertheless, this technique can explore other aspects of biofilm, such as adhesivity, viscosity, and rugosity, as has already been shown for $P$. aeruginosa cultured on sheets of polyvinyl chloride. ${ }^{34}$

All cultures from ETT biofilms were positive, whatever the duration of intubation. The populations of microorganisms were not exactly similar to tracheal aspirates. The ETT samples that had been rinsed out with saline solution to eliminate labile tracheal secretions did not show differences in colonization rates compared with the first 6 samples, which were not rinsed (data not shown). Not all microorganisms isolated on the ETT were considered pathogenic and are commonly found in the oropharynx. As shown in previous studies, pathogenic strains were also found in ETTs, $2,3,25,34$ frequently without clinical importance. In our study, for the 4 VAP cases, the microorganisms involved were found in the ETT biofilm after appropriate antibiotic therapy and clinical improvement. This may confirm the reservoir effect of biofilm for bacteria.

In our study, biofilm was found in all the tubes analyzed, even after only $24 \mathrm{~h}$ of intubation, in concordance with previous studies. ${ }^{4,35}$ Bacteria were observed in $73 \%$ of the cases, mainly Pseudomonas species and Enterobacteriaceae. ${ }^{32}$ Feldman et $\mathrm{l}^{36}$ found the same microorganisms on the ETT biofilm as the microorganisms involved in VAP, in subjects treated for VAP. Adair et $\mathrm{al}^{9}$ observed this correlation in $70 \%$ of cases. It may be interesting to note that, in our study, C. albicans was isolated in $25 \%$ of cases, each time associated with Pseudomonas. This association has been often described, and there may exist an interaction between these 2 organisms. ${ }^{37-40}$ It has been shown that $C$. albicans impedes alveolar macrophage function and is associated with the presence of $P$. aeruginosa pneumonia in rats. ${ }^{40}$

Studies with nonculturing technique using quantitative polymerase chain reaction and gene surveys targeting $16 \mathrm{~S}$ rARN genes showed a large quantity of bacterial DNA on 3 segments of ETT (proximal, medial, and distal). ${ }^{41,42}$ With this technique, ETT were found to be colonized within $24 \mathrm{~h}$, without correlation between bacterial load and time, but a longer intubation period increased the opportunity of pathogenic strains to proliferate.

The pathogenesis of VAP is multifactorial. ${ }^{2}$ Aspiration of oropharyngeally-contaminated secretions or leakage of bacteria around the endotracheal tube cuff is probably the primary route of bacterial colonization of the distal air- 
ways, but biofilm could also contribute, ${ }^{41,42-45}$ and several studies have attempted to prevent, eliminate, or decontaminate the biofilm. ${ }^{46}$ In vitro studies demonstrated that tubes covered with an antiseptic solution did not present biofilm $^{47}$ or did so to a lesser degree. ${ }^{13}$ These results were confirmed experimentally with tubes covered with silver sulfadiazine and chlorhexidine, ${ }^{13}$ or silver-coated ETT. ${ }^{48}$ Berra et $\mathrm{al}^{31}$ have concluded that silver-coated ETT in ICU patients decreased overall bacterial colonization. The North American Silver-Coated Endotracheal Tube (NASCENT) study included 2,003 subjects intubated with either a standard tube or a silver-coated ETT, ${ }^{17}$ showing a decrease in the VAP rate from $7.5 \%$ to $4.8 \%$ without effect on mechanical ventilation duration or mortality. A removable stalk with an inflatable balloon to eliminate adhered mucus inside the ETT has also been proposed. ${ }^{30,33}$ In a short clinical trial, this device appeared safe, and could prevent or reduce secretion deposits. ${ }^{18}$

\section{Conclusions}

This study was observational and confirms that biofilm is present uniformly in all ETTs, is most often polymicrobial, and develops very quickly. The technique of measurement may indicate great differences in its apparent thickness due to loosening of accumulated layer secretions, but the ETT biofilm remains present even after soft rinse.

\section{REFERENCES}

1. Bekaert M, Timsit JF, Vansteelandt S, Depuydt P, Vesin A, Garrouste-Orgeas M, et al. Attributable mortality of ventilator-associated pneumonia: a reappraisal using causal analysis. Am J Respir Crit Care Med 2011;184(10):1133-1139.

2. Chastre J, Fagon JY. Ventilator-associated pneumonia. Am J Respir Crit Care Med 2002;165(7):867-903.

3. Ibrahim EH, Tracy L, Hill C, Fraser VJ, Kollef MH. The occurrence of ventilator-associated pneumonia in a community hospital: risk factors and clinical outcomes. Chest 2001;120(2):555-561.

4. Pneumatikos IA, Dragoumanis CK, Bouros DE. Ventilator-associated pneumonia or endotracheal tube-associated pneumonia? An approach to the pathogenesis and preventive strategies emphasizing the importance of endotracheal tube. Anesthesiology 2009;110(3):673680.

5. Vassilakopoulos T. The patient-ventilator interaction has a third player: the endotracheal tube. Chest 2009;136(4):957-959.

6. Costerton JW, Stewart PS, Greenberg EP. Bacterial biofilms: a common cause of persistent infections. Science 1999;284(5418):13181322.

7. Donlan RM, Costerton JW. Biofilms: survival mechanisms of clinically relevant microorganisms. Clin Microbiol Rev 2002;15(2):167193.

8. Girou E, Buu-Hoi A, Stephan F, Novara A, Gutmann L, Safar M, Fagon JY. Airway colonisation in long-term mechanically ventilated patients. Effect of semi-recumbent position and continuous subglottic suctioning. Intensive Care Med 2004;30(2):225-233.

9. Adair CG, Gorman SP, Feron BM, Byers LM, Jones DS, Goldsmith $\mathrm{CE}$, et al. Implications of endotracheal tube biofilm for ventilatorassociated pneumonia. Intensive Care Med 1999;25(10):1072-1076.
10. Craven DE. Preventing ventilator-associated pneumonia in adults: sowing seeds of change. Chest 2006;130(1):251-260.

11. Sottile FD, Marrie TJ, Prough DS, Hobgood CD, Gower DJ, Webb LX, et al. Nosocomial pulmonary infection: possible etiologic significance of bacterial adhesion to endotracheal tubes. Crit Care Med 1986;14(4):265-270.

12. Bauer TT, Torres A, Ferrer R, Heyer CM, Schultze-Werninghaus G, Rasche K. Biofilm formation in endotracheal tubes: association between pneumonia and the persistence of pathogens. Monaldi Arch Chest Dis 2002;57(1):84-87.

13. Ramirez P, Ferrer M, Torres A. Prevention measures for ventilatorassociated pneumonia: a new focus on the endotracheal tube. Curr Opin Infect Dis 2007;20(2):190-197.

14. Stewart PS, Costerton JW. Antibiotic resistance of bacteria in biofilms. Lancet 2001;358(9276):135-138.

15. Berra L, Curto F, Li Bassi G, Laquerriere P, Pitts B, Baccarelli A, Kolobow T. Antimicrobial-coated endotracheal tubes: an experimental study. Intensive Care Med 2008;34(6):1020-1029.

16. Orhan-Sungur M, Akça O. Antiseptic impregnated endotracheal tubes, biofilms, and ventilator-associated pneumonia. Crit Care Med 2006; 34(11):2855-2857.

17. Kollef MH, Afessa B, Anzueto A, Veremakis C, Kerr KM, Margolis $\mathrm{BD}$, et al. Silver-coated endotracheal tubes and incidence of ventilator-associated pneumonia: the NASCENT randomized trial. JAMA 2008;300(7):805-813.

18. Berra L, Coppadoro A, Bittner EA, Kolobow T, Laquerriere P, Pohlmann JR, et al. A clinical assessment of the Mucus Shaver: a device to keep the endotracheal tube free from secretions. Crit Care Med 2012;40(1):119-124.

19. American Thoracic Society, Infectious Diseases Society of America. Guidelines for the management of adults with hospital-acquired, ventilator-associated, and healthcare-associated pneumonia. Am J Respir Crit Care Med 2005;171(4):388-416.

20. Lacherade JC, Auburtin M, Cerf C, Van de Louw A, Soufir L, Rebufat $\mathrm{Y}$, et al. Impact of humidification systems on ventilatorassociated pneumonia: a randomized multicenter trial. Am J Respir Crit Care Med 2005;172(10):1276-1282.

21. Louis B, Glass GM, Fredberg JJ. Pulmonary airway area by the two-microphone acoustic reflection method. J Appl Physiol 1994; 76(5):2234-2240.

22. Van Surell C, Louis B, Lofaso F, Beydon L, Brochard L, Harf A, et al. Acoustic method to estimate the longitudinal area profile of endotracheal tubes. Am J Respir Crit Care Med 1994;149(1):28-33.

23. Jaber S, Pigeot J, Fodil R, Maggiore S, Harf A, Isabey D, et al. Long-term effects of different humidification systems on endotracheal tube patency: evaluation by the acoustic reflection method. Anesthesiology 2004;100(4):782-788.

24. Dufrêne YF. Atomic force microscopy, a powerful tool in microbiology. J Bacteriol 2002;184(19):5205-5213.

25. Villafane MC, Cinnella G, Lofaso F, Isabey D, Harf A, Lemaire F, Brochard L. Gradual reduction of endotracheal tube diameter during mechanical ventilation via different humidification devices. Anesthesiology 1996;85(6):1341-1349.

26. Boqué MC, Gualis B, Sandiumenge A, Rello J. Endotracheal tube intraluminal diameter narrowing after mechanical ventilation: use of acoustic reflectometry. Intensive Care Med 2004;30(12):2204-2209.

27. Morán I, Cabello B, Manero E, Mancebo J. Comparison of the effects of two humidifier systems on endotracheal tube resistance. Intensive Care Med 2011;37(11):1773-1779.

28. Shah C, Kollef MH. Endotracheal tube intraluminal volume loss among mechanically ventilated patients. Crit Care Med 2004;32(1): $120-125$. 


\section{ETT Biofilm In InTENSIVE CARE}

29. Wilson AM, Gray DM, Thomas JG. Increases in endotracheal tube resistance are unpredictable relative to duration of intubation. Chest 2009;136(4):1006-1013.

30. Berra L, Curto F, Li Bassi G, Laquerriere P, Baccarelli A, Kolobow T. Antibacterial-coated tracheal tubes cleaned with the Mucus Shaver: a novel method to retain long-term bactericidal activity of coated tracheal tubes. Intensive Care Med 2006;32(6):888-893.

31. Berra L, Kolobow T, Laquerriere P, Pitts B, Bramati S, Pohlmann J, et al. Internally coated endotracheal tubes with silver sulfadiazine in polyurethane to prevent bacterial colonization: a clinical trial. Intensive Care Med 2008;34(6):1030-1037.

32. Inglis TJ, Lim TM, Ng ML, Tang EK, Hui KP. Structural features of tracheal tube biofilm formed during prolonged mechanical ventilation. Chest 1995;108(4):1049-1052.

33. Kolobow T, Berra L, Li Bassi G, Curto F. Novel system for complete removal of secretions within the endotracheal tube: the Mucus Shaver. Anesthesiology 2005;102(5):1063-1065.

34. Gorman SP, McGovern JG, Woolfson AD, Adair CG, Jones DS. The concomitant development of poly(vinyl chloride)-related biofilm and antimicrobial resistance in relation to ventilator-associated pneumonia. Biomaterials 2001;22(20):2741-2747.

35. Gil-Perotin S, Ramirez P, Marti V, Sahuquillo JM, Gonzalez E, Calleja I, et al. Implications of endotracheal tube biofilm in ventilator-associated pneumonia response: a state of concept. Crit Care 2012;16(3):R93.

36. Feldman C, Kassel M, Cantrell J, Kaka S, Morar R, Goolam Mahomed A, Philips JI. The presence and sequence of endotracheal tube colonization in patients undergoing mechanical ventilation. Eur Respir J 1999;13(3):546-551.

37. Ader F, Faure K, Guery B, Nseir S. [Pseudomonas aeruginosa and Candida albicans interaction in the respiratory tract: from pathophysiology to a therapeutic perspective]. Pathol Biol (Paris) 2008; 56(3):164-169.
38. Azoulay E, Timsit JF, Tafflet M, de Lassence A, Darmon M, Zahar JR, et al. Candida colonization of the respiratory tract and subsequent pseudomonas ventilator-associated pneumonia. Chest 2006; 129(1):110-117.

39. Hogan DA, Kolter R. Pseudomonas-Candida interactions: an ecological role for virulence factors. Science 2002;296(5576):2229-2232.

40. Roux D, Gaudry S, Dreyfuss D, El-Benna J, de Prost N, Denamur E, et al. Candida albicans impairs macrophage function and facilitates Pseudomonas aeruginosa pneumonia in rat. Crit Care Med 2009; 37(3): 1062-1067.

41. Cairns S, Thomas JG, Hooper SJ, Wise MP, Frost PJ, Wilson MJ, et al. Molecular analysis of microbial communities in endotracheal tube biofilms. PLoS One 2011;6(3):e14759.

42. Perkins SD, Woeltje KF, Angenent LT. Endotracheal tube biofilm inoculation of oral flora and subsequent colonization of opportunistic pathogens. Int J Med Microbiol 2010;300(7):503-511.

43. Cairns S, Thomas JG, Hooper SJ, Wise MP, Frost PJ, Wilson MJ, et al. Molecular analysis of microbial communities in endotracheal tube biofilms. PLoS One;6(3):e14759.

44. Berra L, Sampson J, Fumagalli J, Panigada M, Kolobow T. Alternative approaches to ventilator-associated pneumonia prevention. Minerva Anestesiol 2011;77(3):323-333.

45. Deem S, Treggiari MM. New endotracheal tubes designed to prevent ventilator-associated pneumonia: do they make a difference? Respir Care 2010;55(8):1046-1055.

46. Lorente L, Blot S, Rello J. New issues and controversies in the prevention of ventilator-associated pneumonia. Am J Respir Crit Care Med 2010;182(7):870-876.

47. Pacheco-Fowler V, Gaonkar T, Wyer PC, Modak S. Antiseptic impregnated endotracheal tubes for the prevention of bacterial colonization. J Hosp Infect 2004;57(2):170-174.

48. Olson ME, Harmon BG, Kollef MH. Silver-coated endotracheal tubes associated with reduced bacterial burden in the lungs of mechanically ventilated dogs. Chest 2002;121(3):863-870.

This article is approved for Continuing Respiratory Care Education credit. For information and to obtain your CRCE

(free to AARC members) visit

www.rcjournal.com

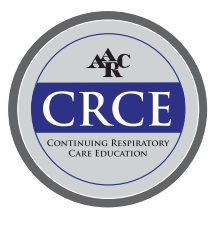

